\title{
PLASTIC DEFORMATION IN BRITTLE AND DUCTILE FRACTURE†
}

\author{
D. C. DRUCKER $†$ and J. R. RICE $\$$ \\ Division of Engineering, Brown University, Providence, R.I. 02912, U.S.A.
}

\begin{abstract}
An effort is made to cover the full elastic-plastic range from the very troublesome fractures which initiate and propagate at nominal or net stress well down in the elastic range to the common yet more easily understandable and preventable fractures at fully plastic or limit load conditions. Similarities and differences of behavior between steels which are highly rate-sensitive and aluminum alloys or other rather insensitive materials are examined. The very marked distinctions between the very special extremes of plane stress and plane strain are brought out along with their relevance to the failure of complex structures and elements. In contrast, the need to consider bending in most shell structures is emphasized. A demonstration is given of the likelihood in the laboratory, but even more so in the field, of confusing limit load fractures with low stress fractures.

Crack extension under plane strain conditions is studied in some detail, and the important role of progressive blunting is indicated both in limiting maximum achievable stresses and providing a small region of intense strain in which ductile fracture mechanisms are operative. Comparison with appropriate microstructural dimensions leads to a rationale for minimum thickness dimensions for plane strain fracture. Plane stress yield patterns in cracked sheets are shown to be greatly sensitive to the yield criterion. The line plastic zone Dugdale model provides a correct solution for a non-hardening Tresca material, but diffuse zones result for a Mises material. The important role of thickness direction anisotropy is indicated. Stable extension under increasing load appears as a possible consequence of crack advance into previously deformed material. Conditions for stable vs. abrupt growth, the appropriateness of energy balance approaches, and plastic limit load calculations are also studied. An attempt is made to place all in perspective.
\end{abstract}

\section{INTRODUCTION}

Bотн authors have prepared fairly extensive surveys relating to our present subject [1-4] in the past few years. We therefore present here a brief review of plasticity aspects of fracture which focuses on recent developments and viewpoints along with suggestions for future study.

Fracturing with contained plasticity at a crack tip is considered first. The relevance of the Irwin-Williams elastic singularity in controlling small scale yielding is discussed, and a path independent line integral technique leading to elastic-plastic analyses is outlined. Plane strain is examined in some detail as a fairly complete picture has been developed for this case. The hydrostatic stress elevation directly ahead of the tip increases rapidly with strain hardening. Perhaps surprisingly, for a perfectly sharp crack the most extensive straining appears above and below the tip rather than directly ahead when the conventional assumption of small geometry changes is made. Attention to the actual large geometry changes in progressive blunting of the sharp tip reveals that an intense strain region is created directly ahead over a size scale comparable to the tip opening displacement. A more quantitative study of the ductile or brittle fracture mechanisms which are operative within this intense strain region requires inclusion of progressive blunting. Strain hardening serves to elevate near tip stresses but the loss of triaxiality due to blunting effectively limits the maximum stress achievable over any

Written and updated version of oral presentation at National Symposium on Fracture Mechanics, Lehigh University, Bethlehem. Pennsylvania, June 1967. Grateful acknowledgement is made to the Advanced Research Projects Agency for support of research leading to results presented here.

$\ddagger$ L. Herbert Ballou University Professor. Presently Dean of Engineering College, University of Illinois.

\$Associate Professor of Engineering. 
reasonable microstructural size scale. This suggests an abruptness of transitional behavior.

Little progress has been made with the three-dimensional analysis of cracked plate (sheet) materials, but the character of near tip fields in two-dimensional plane stress has been clarified. The plane stress plasticity patterns are strongly dependent on the yield surface employed; the line plastic zone Dugdale model is an exact two-dimensional non-hardening solution for a Tresca material, whereas diffuse plastic zones appear in a Mises material. With physical interpretation of the two-dimensional discontinuity as deformation in a band confined to a sheet thickness width, an entirely different dependence of local strain on thickness results. Anisotropy (thickness vs. in-plane directions) is suspected as contributing to the yielding patterns actually observed in metal sheets. The biaxial tension plane stress yield surfaces for sheets isotropic in their plane depend critically on the properties in the thickness direction.

The true incremental nature of plastic stress-strain relations leads to a view of crack extension quite different from that for a non-linear elastic material with similar monotonic loading behavior. Dominant features of fracture in ductile sheet materials are stable crack growth under increasing deformation due to advance into previously strained material, with final fracture as an instability in the growth process. The McClintock anti-plane shear theory is reviewed and cast in a form showing its equivalence to an alternate analysis of growth in terms of a 'resistance curve'.

Attention then is turned to energy balance concepts in more detail. The unstable or falling portion of the local nominal stress-strain curve is seen to provide the equivalent of a surface energy. However, because the nominal values enter, the magnitude of this energy is strongly dependent on the geometry of the structure and its environment as well as on the detailed process of fracture. Differences between rate-sensitive and insensitive materials show up in the presence or absence of a large 'barrier' to the initiation of fracture as opposed to its propagation.

Finally, consideration is given to plastic limit load calculations and the likclihood that even in simple plate and shell structures, out-of-plane bending will control. Primarily but not entirely for this reason, many such fractures in the laboratory and in the field which have been reported as low stress brittle fractures turn out in fact to be limit load failures. Once the plastic limit load is approached, local strains can become extremely large and lead to failure of highly ductile materials through void coalescence processes.

\section{ELASTIC-PLASTIC STRESS ANALYSIS OF CRACKED BODIES: PRELIMINARIES}

Elastic stress analyses provide a convenient starting point for the discussion of the elastic-plastic case. Irwin [5] and Williams [6] have shown two dimensional plane stress and plane strain near crack tip elastic stress fields to have a characteristic structure

$$
\sigma_{i j}=\frac{K}{V_{r}} f_{i j}(\theta)+\text { other terms bounded at the crack tip. }
$$

Here $r$ is distance from the tip and the set of functions $f_{10}(\theta)$ of the polar orientation angle are the same for all symmetrically loaded configurations, Fig. 1. These are normalized so that $K / V(2 \pi r)$ is the dominant tension directly ahead of the crack tip. An extensive tabulation of stress intensity factors $K$ has been given by Paris and Sih [7]. 


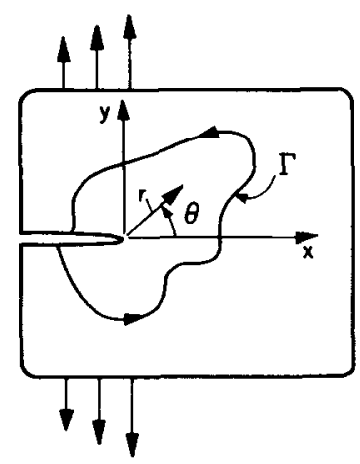

Fig. 1. Crack in two-dimensional deformation field. $J$ integral has same value for all paths such as $\Gamma$.

The basic similarity inherent in elastic stress fields is the theoretical basis for the organization of fracture behavior through "elastic fracture mechanics' [8-10].

Purely elastic fracture mechanics studies of crack tip stresses are useful but limited. For example, the in-plane stresses for plane stress and strain are the same for elastic behavior but are very different in the plastic range. Also, the incremental nature of plastic stress-strain relations leads to a view of fracture instability not anticipated from elastic considerations. Further, rather extensive contained yielding or fully plastic conditions often prevail at fracture. This is the case with the tougher ductile metals in use and with those which one would hope to develop in the high strength range. Also, the necessary compactness of laboratory specimens sometimes may force a correlation of real or apparent low stress level service behavior with high stress level specimen behavior. It is worth repeating an earlier warning [34,3] that many of the fractures of complex metal structures which look brittle and often are reported as brittle are fractures at fully plastic or limit load conditions.

A precise statement of our notion that the elastic singularity governs small scale contained yielding is embodied in Rice's boundary layer formulation $[2,4,11]$. Here a crack in a structural member is replaced by a semi-infinite crack in an infinite plane sheet. Actual (and generally complicated) boundary conditions for the plastic zone or enclave are replaced by the requirement of an asymptotic approach to the surrounding singularity:

$$
\sigma_{i j} \rightarrow \frac{K}{\sqrt{ } r} f_{i j}(\theta) \quad \text { as } \quad r \rightarrow \infty
$$

An elastic-plastic problem then is solved. Inherent mathematical simplifications permit small scale yielding solutions in cases where a complete analysis is unmanageable. While mathematically exact only to within a first term Taylor development of complete solutions in applied load, small scale yielding solutions are good approximations up to substantial fractions (typically, $\frac{1}{2}$ ) of general yielding loads [2,4].

Progress in the understanding of behavior in tension has followed on increasingly reliable numerical-computer treatments, based recently on finite element methods $[12,13]$, and on the application of an encrgy line integral [14-16] to the analytical study of near tip fields employing a deformation or total theory of plasticity. Specialized to the 
case of a crack the latter technique identifies the integral [14]

$$
J=\int_{\Gamma}\left[W(\boldsymbol{\epsilon}) \mathrm{d} y-\mathbf{T} \cdot \frac{\partial \mathbf{u}}{\partial x} \mathrm{~d} s\right]
$$

as independent of the path on circuits l'surrounding the crack tip, Fig. 1. Here $\mathbf{T}$ is the traction vector acting on the outer side of $\mathrm{l}, \mathbf{u}$ is displacement, and $s$ is arc length. In the deformation plasticity approach employed, an energy density $W(\epsilon)=\int \sigma_{i j} \mathrm{~d} \epsilon_{i j}$ is admitted by the stress-strain relations. Keys to usefulness lie both in the ability to distort the integration path and in the ease of assigning exact or approximate values to $J$. For example, small scale yielding in plane strain leads to

$$
J=\frac{\left(1-\nu^{2}\right)}{E} K^{2}
$$

It is not coincidental that this equals Irwin's linear elastic energy release rate. Indeed, it may be shown [4] that $J$ is always the energy release rate for an elastic material specified by the energy density $W(\epsilon)$. Equation (3), in relating the near tip field to $J$, generalizes Irwin's relation between linear stress intensities and the energy rate.

Rice and Rosengren [16] chose a small circular path for $\Gamma$ and let the radius shrink to zero to show that the integrand terms in (3) must, in angular average, exhibit a $1 / r$ singularity. These terms are of order stress times displacement gradient so that one anticipates an asymptotic structure.

$$
\sigma_{i j} \epsilon_{i j} \rightarrow \frac{\text { a function of } \theta}{r} \text { as } r \rightarrow 0
$$

This presumes no line of displacement discontinuity emanating from the tip, although as we shall see, such lines can and do sometimes exist in a non-hardening material.

\section{PLANE STRAIN DEFORMATION NEAR CRACKS}

Conditions approaching the plane strain idealization result from constraint of surrounding elastic material when the in-plane dimensions of plastically deforming regions are small compared to the thickness dimension of a cracked plate. Such conditions generally represent the minimum toughness configuration for structural metals $[8,10]$.

Consider first contained plane strain deformation in a non-hardening material. The principal in-plane shear stress in the highly strained regions near the tip equals the yield value $\tau_{0}$, and a stress distribution depending only on the polar angle $\theta$ is approached as $r \rightarrow 0$. Following [14], the stress distribution in the fully plastic deforming region may be obtained through slip line theory[17]. The resulting Prandt field and associated stresses are indicated in Fig. 2, where constant stress regions $A$ and $B$ are joined by a centered fan $C$. Strains are bounded in the constant stress regions, but the shear $\gamma_{r \theta}$ exhibits a singularity as the crack tip is approached in the fan. The very near tip vertical displacement $u_{u}$ varies with $\theta$ in the fan, so that an opening displacement results at the tip. As $r \rightarrow 0$ in the fan [14]

$$
\gamma_{r \theta} \rightarrow \gamma_{0} \frac{R(\theta)}{r}, \quad u_{\eta \prime} \rightarrow \gamma_{0} \int_{\pi / 4}^{\theta} R(\phi) \sin \phi \mathrm{d} \phi
$$




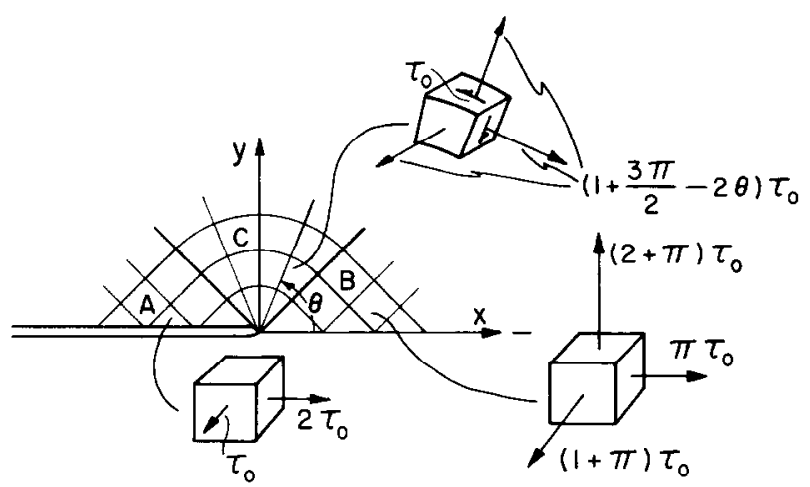

Fig. 2. Slip line construction of limiting stress state near a crack tip, for contained plastic yielding of a non-hardening material under plane strain conditions.

Here $\gamma_{0}$ is the initial yield strain in shear and $R(\theta)$ is a function undetermined by the slip line analysis, but which may be viewed as an approximate indication of the extent of the strained region which is deforming in an almost purely plastic manner. Employing a deformation plasticity theory and the $J$ integral, an averaged value is set by [14]

$$
J=2 \tau_{0} \int_{\pi / 4}^{3 \pi / 4} R(\theta)[\cos \theta+(1+3 \pi / 2-2 \theta) \sin \theta] \mathrm{d} \theta .
$$

For small scale yielding it would appear appropriate from recent etching studies $[18,19]$ to choose a highly strained region of the form

$$
R(\theta) \approx R_{0} \cos 2(\theta-\pi / 2)
$$

extending into the fan region but approaching the tip along fan boundaries as in Fig. 3(a). Thus from (4) and (7), the approximate extent of a small scale yielding plastic zone is

$$
R_{0}=\frac{3(1-\nu)}{\sqrt{ } 2(2+\pi)}\left(\frac{K}{2 \tau_{0}}\right)^{2}=0 \cdot 29\left(\frac{K}{2 \tau_{0}}\right)^{2} \text { for } \nu-0 \cdot 3 .
$$

Letting $\delta_{t}=2 u_{y}(3 \pi / 4)$, the total opening displacennent between upper and lower crack surfaces at the tip is then approximated by

$$
\delta_{t} \approx \frac{1-\nu}{2+\pi} \frac{K^{2}}{G \tau_{0}}=1.9 \gamma_{0} R_{0}
$$

We note in the next section the important role of the opening displacement for fracture micromechanisms. No analysis is presently available for the large scale yielding range and this is an important goal of future research. A speculation on the large extension of the plastic region at a load still well below the limit load is shown in Fig. 3(b). We consider an edge crack in an infinite width body and presume the plastic region to be contained but large compared to crack size. Further, consider the material as elastically incompressible so that slip lines may be drawn in the plastic region. A state of nearly 


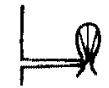

(a) SMALL SCALE YIELDING

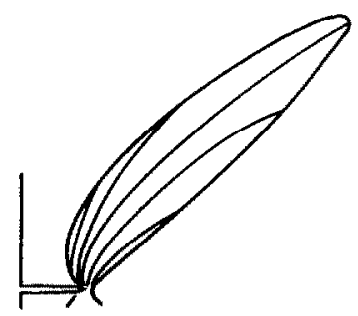

(b) SPECULATION ON LARGE SCALE YIELDING, BUT PRIOR TO LIMIT LOAD

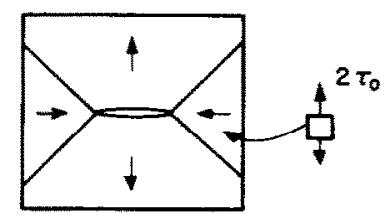

(d) LIMIT FIELD FOR INTERNAL NOTCH

Fig. 3. The progression of plastic yielding in plane strain, from small scale contained yielding to fully plastic limit conditions.

simple tension at $2 \tau_{0}$ is anticipated toward the outer extremity of the plastic zone with slip lines near $45^{\circ}$. Of all the radial slip lines in the near tip fan, only the initially vertical slip line will result in this stress state when rotated to $45^{\circ}$. Thus we have drawn a plastic region with the initially vertical slip line rotating and extending toward the extremity of the plastic region, while other slip lines are extinguished on contact with the elasticplastic boundary. A similar construction for the $90^{\circ} \mathrm{V}$ notch would closely duplicate the plastic regions observed prior to joining for the double edge notch configuration studied numerically by Marcal and King [13].

Important differences in the near crack tip stress and strain distributions in the large scale yielding range are illustrated by the limit flow fields for a non-hardening material in Figs. 3(c) and (d). A deep double edge notch specimen retains the hydrostatic stress elevation to limit load, whereas the internally notched and single edge notch specimens do not [34]. For consistency of the latter cases with the large scale yielding pattern prior to limit load in Fig. 3(b), the radius of curvature of the initially vertical slip line at the tip must decrease toward zero as limit conditions are approached, so as to match the discontinuities at $\pm 45^{\circ}$ with the crack line in Fig. 3(d). This means that unloading will occur. The great differences in both stress and strain fields near the tip in constrained vs. unconstrained configurations suggests that a single critical crack opening displacement fracture criterion [20] will not correlate observed behavior for all configurations. Such simple measures of near tip deformations may prove extremely useful for limited groups of specimens having similar near tip stress fields. But no one-parameter characterization of the near tip field, paralleling the stress intensity factor in the small scale yielding range, can apply for all possible patterns of large scale yielding.

Hutchinson [15] and Rice and Rosengren [16] have obtained the structure of near tip plane strain singularities in materials exhibiting a power law relation

$$
\tau=\tau_{0}\left(\gamma / \gamma_{0}\right)^{N} \text { for } \gamma>\gamma_{0}
$$


between principal shear stress and strain beyond the initial yield point. It is necessary to assume elastic as well as plastic incompressibility in plane strain, and this causes some difficulty in the interpretation of solutions. Equation (5) is the starting point so that the near tip $r$ dependence is known, and a numerical solution of an ordinary differential equation provides the $\theta$ dependence. The maximum resolved in-plane shear stress and strain take the forms

$$
\tau \rightarrow \tau_{0}\left[\frac{R(\theta)}{r}\right]^{N /(1+N)}, \gamma \rightarrow \gamma_{0}\left[\frac{R(\theta)}{r}\right]^{1 /(1+N)} \text { as } r \rightarrow 0
$$

$R(\theta)$ is a known function of $J$ and $\theta$ for each value of the hardening exponent $N$. The curves $r=$ constant $\times R(\theta)$ give the shape of constant shear strain lines near the tip, and we may view $R(\theta)$ as an approximate indication of the extent of the plastically deforming region along a ray from the tip at angle $\theta$. Further the ratio of the mean normal inplane stress, $p=\left(\sigma_{x x}+\sigma_{y y}\right) / 2$, to the principal shear, $\tau$, approaches a function of $\theta$ only, as does the principal shear direction also. Thus the singular deformation field involves proportional loading, so that the same form of singularity would result in a power law hardening material treated through an incremental theory. Polar plots of $\tau_{0} \gamma_{0} R(\theta) / J$ (dimensionless) and $p / \tau$ are shown in Fig. 4 for $N=0 \cdot 005,0 \cdot 1$ and $0 \cdot 3$. More detailed numerical results are presented in $[15,16]$. Results for the smallest value of $N$ appear to represent the limit of the solution as $N \rightarrow 0^{+}$. The corresponding stress field then agrees closely with the non-hardening distribution of Fig. 2. Again, the largest strains occur above and below the tip, rather than directly ahead; but stress triaxiality directly ahead of the crack rises quite rapidly with the hardening exponent.

Two factors make interpretation of these results difficult. The first is that only the dominant singularity is given, not the complete solution. The second is that actual elastic compressibility is certain to be important in view of the high triaxiality. The first point may be somewhat clarified by examining the anti-plane strain case in which a complete solution for power law hardening materials is known[11]. Anti-plane strain dominant singularities may be found through an analogous procedure. It turns out that for the small scale yielding boundary layer type solution, these dominant singularities represent the complete solution within the plastic region. The same is not true for large scale yielding. Thus it may be the case that the plane strain dominant singularities outlined above are also complete small scale yielding solutions for an incompressible material. It is certain that they cannot be complete solutions for large scale yielding. Further, one finds in large scale yielding anti-plane strain that it is meaningless to speak of dominant singularities with light strain hardening. While mathematically such singularities dominate as $r \rightarrow 0$, strain magnitudes become too large for the assumptions of the theory before all other terms of the complete solution are negligible in comparison. Indeed, no unique near tip strain field exists in the nonhardening limit $N=0$. It is clear from the variety of fields in Fig. 3 that the same statements apply in plane strain.

Actual elastic compressibility becomes less important the more the equivalent plastic strain exceeds initial yield strains. But compressibility considerably affects the behavior in the neighborhood of first yield in plane strain, particularly with high triaxiality. For example, one may show for a Mises material that the principal in-plane shear strain at first yielding is

$$
\gamma_{Y}=\gamma_{0}\left[1-\frac{(1-2 \nu)^{2}}{3}\left(\rho / \tau_{0}\right)^{2}\right]^{1 / 2}
$$




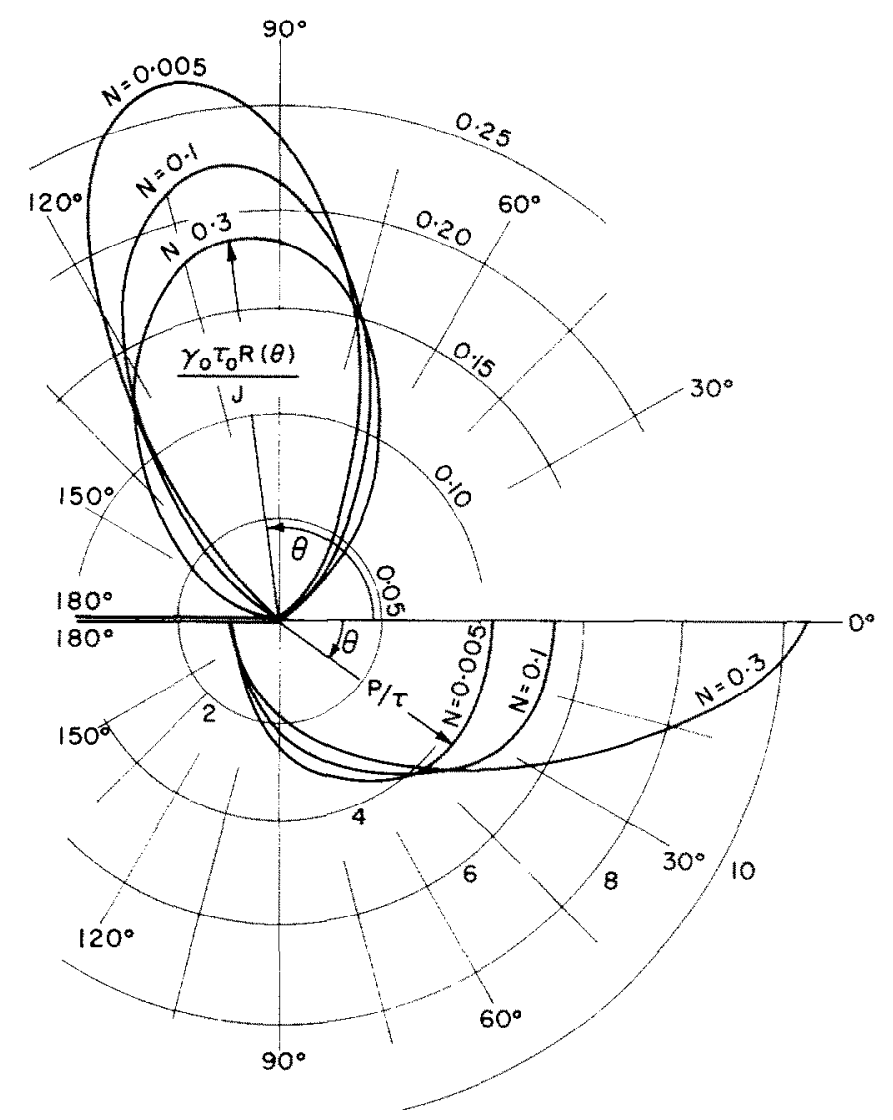

Fig. 4. Plane straining of material hardening according to the power law $\tau=\tau_{0}\left(\gamma / \gamma_{0}\right)^{N}$. Upper curves: shape of $R(\theta)$ in near tip equivalent strain expression $\gamma \rightarrow \gamma_{0}[R(\theta) / r]^{1 /(1+n)}$. Lower curves: ratio of mean normal stress $p$ to equivalent shear stress.

where $p$ is the mean in-plane normal stress. Choosing $p=(1+\pi) \pi_{0}$ as the maximum mean stress in a non-hardening material, one finds $\gamma_{Y} \approx 0.3 \gamma_{0}$ for $\nu=0.3$. Returning to the curves of Fig. 4 , since the triaxiality is large in quadrant $0<\theta<90^{\circ}$, the first yicld strain for $\nu<1 / 2$ will be considerably less than $\gamma_{0}$ in that region. Thus, presuming without any real justification that the lobes represent small scale elastic-plastic boundaries in incompressible materials, one expects a shifting forward of the boundary lobes in actual compressible materials. This makes direct comparison with experiment difficult, but the general shape predicted for the highly deformed region does correspond closely to results of etching studies [18, 19].

The limited state of analytical progress in the relatively simple case of plane strain suggests that computer based numerical methods must be relied upon to fill in the many missing details. Such methods as presently formulated are notably poor near singularities and fracture mechanics is, in a sense, the judicious interpretation of crack tip singular fields of continuum analyses. Equation (5) and the asymptotic treatments of near tip fields in this section are of special pertinence to the computer accuracy problem. At an elementary level, they provide an aid for interpreting solutions 
in regions of otherwise questionable accuracy. More importantly, they provide a guide for developing numerical treatments with sufficient freedom in deformation modes so as to closely duplicate actual deformation patterns.

\section{THE VERY NEAR TIP REGION IN PLANE STRAIN FRACTURE AND MINI- MUM SHEET THICKNESS REQUIREMENTS}

The ductile fracture mechanism of void formation from inclusions and subsequent growth [21.22] sets the mean inclusion spacing as a characteristic length scale over which continuum solutions must be examined for a fracture criterion. Pure cleavage or partial cleavage facet formation with subsequent ductile or ductile plus cleavage joining sets a size scale of one or a few grains. Thus the region of interest is very near the tip and in structural metals is very small compared to the plastic zone at fracture.

Figure 5(a) for a non-hardening material presents the same slip line field as Fig. 2 . but now the picture has been magnified by a large factor of order $1 / \gamma_{0}$. The crack tip no longer appears sharp on this scale, due to the progressive blunting by plastic deformation. We have noted that the sharp crack solution leads to no intense strain concentration directly ahead. The picture changes drastically near the blunted tip, with the fan $C$ becoming non-centered and focusing into a small region $D$ (Fig. 5(a)) of intense deformation. This region extends over a distance of approximately $2 \delta_{t}$ for a semi-circular tip with associated exponential spiral slip lines. While a detailed analysis of blunting has not yet been carried out, Rice[14] has noted that procedures employed by Wang [23] can be adapted to the contained yielding case with the sharp crack solution setting boundary conditions on the blunting analysis. Material points would be subjected to a stress well above tensile yield (due to the hydrostatic elevation) prior to envelopment by the large strain region, and this could lead to cracking of inclusions so as to provide the void sites for subsequent growth. Stress triaxiality is known [22] to exponentially amplify void growth over average strain.

The influence of strain hardening on tensile stresses directly ahead of the crack is shown in Fig. 5(b) based on a power law analysis. These curves showing $\sigma_{y y}(x$, $0) / 2 \tau_{0}$ were plotted from numerical results obtained by Rice and Rosengren[16]. and represent the prediction of the dominant singular term only. Since it is seen in Fig. 4 that the highly strained region extends primarily above and below the tip and not ahead, the considerable elevation above $2 \tau_{0}$ occurs by hydrostatic stressing and not by strain hardening in the conventional sense. For convenience of illustration, distance from the crack tip is measured in terms of a parameter $R_{0}=J / 5 \gamma_{0} \tau_{0}$. While predicted extents of the plastically strained region vary with hardening exponent, this value of $R_{0}$ is in the range of predicted extents for the hardening exponents employed in Fig. 5(b). Stresses are shown out to a distance of a tenth of $R_{0}$ at which only minor deviations occur from the stress in a non-hardening material. This would appear to be an appropriate utilization of the dominant singularity solution. We presently have no prediction of the fall off of stress magnitudes from the maximum values attained in this small region near the tip. One would expect a tension in the neighborhood of $2 \tau_{0}$ at a distance ahead of the tip of order unity times $R_{0}$. The stresses are not shown over a very near tip region comparable to the opening displacement $\delta_{t}$, since the reduction of triaxiality forced by boundary conditions on the blunted tip is sure to greatly reduce predicted values (which neglect large geometry changes) in this region. The stresses in a non-hardening material will reduce as shown by the dashed line, and at least a leveling off is anticipated in the hardening cases. Thus the maximum stress achiev- 


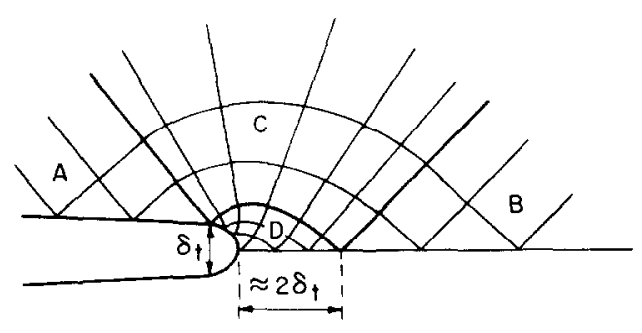

(a)

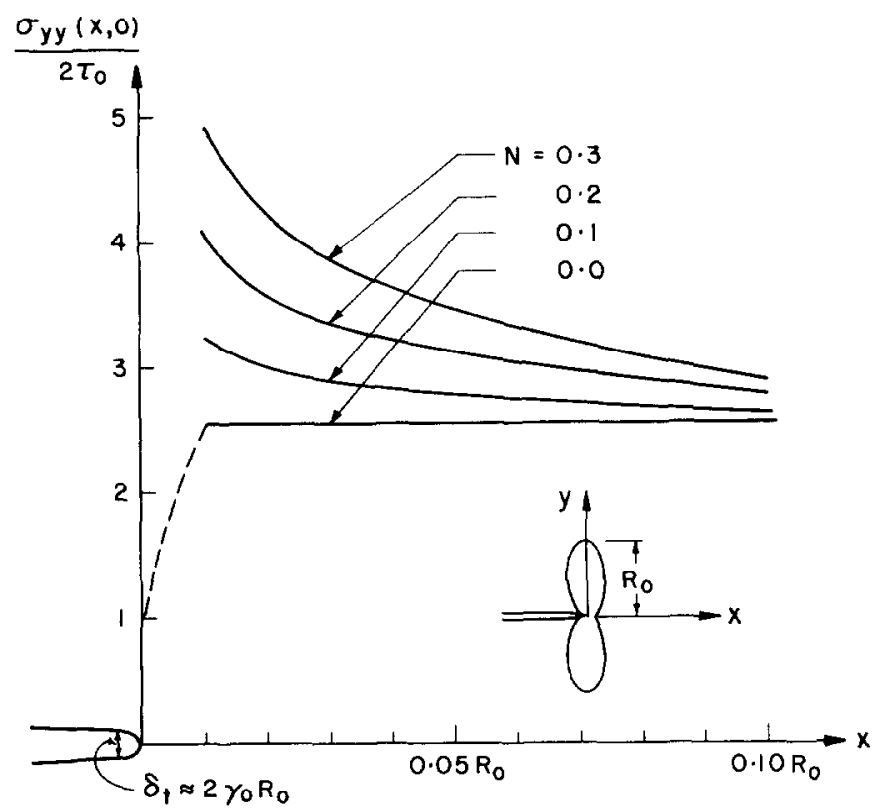

(b)

Fig. 5. Details of the very near tip deformation field in plane strain. (a) Large geometry changes in progressive blunting create a small region $D$ of intense deformation which is not included in a sharp crack analysis based on conventional small strain assumptions. (b) Tensile stress acting directly ahead of the crack tip for various hardening exponents; dashed line indicates fall off of stress in region affected by blunting.

able over any reasonable size scale is limited by blunting, even with continuous hardening under increasing strain. This would suggest an abruptness characteristic of toughness temperature transitions for maximum stress dominated fracture mechanisms as in cleavage [24].

The curves of Fig. 5(b) indicate the greater stresses with hardening for inclusion cracking and/or stable cleavage facet formation prior to the large expansion of cavities thus created when final fracture mechanisms are ductile. This is counterbalanced by a retarding of cavity growth by strain hardening [22]. One would judge from results of Krafft [25] that the latter effect dominates. Fracture studies on the microscale should be carried out with an awareness of the stress and deformation environment 
characteristic of the near tip field in plane strain. Observations based on simple uniaxial stress fields and accompanying strain patterns may not be at all relevant. Also, attention would profitably be directed toward developing laboratory specimens duplicating highly triaxial stress fields over sizeable regions, so as to permit careful studies of plane strain fracture mechanisms.

A stable process of fracture initiation through inclusion cracking or other void mechanism, followed by void growth and coalescence, may occur on a large or a small scale. It necessarily involves very large local strains in a plastic zone which includes a number of initiation sites. Under plane strain conditions and a small scale yielding, the coalescence is likely to occur primarily between voids in the thickness direction and between the first line of voids and the advancing crack. Therefore it seems reasonable to believe that, within a factor of 2 or so, the zone of very large plastic deformation in a structural aluminum alloy should extend a minimum of $50 \mu$ in from the crack tip.

Equating $2 \delta_{t}$ of (10) or $4 \gamma_{0} R_{0}$ to $50 \mu$ shows $R_{0}$, the extent of the plastically deforming region in the plane, to be $50 / 4 \gamma_{0} \mu$ or approximately $100,000 / \sigma_{0} \mathrm{~mm}$, where $\sigma_{0}$ is the yield strength of the alloy in psi. Therefore, a 50,000 psi aluminum alloy requires a minimum plastic zone extent of $2 \mathrm{~mm}$ to envelope a sufficient number of initiation sites.

The sheet or plate thickness to ensure plane strain constraint conditions at and near the midplane of the sheet need not be nearly as large in ratio as for the fully plastic state $[22,35,36]$. Elastic constraint at the boundaries of the plastic enclave will be more effective because portions of the boundary are much closer than $R_{0}$ to the tip of the crack. As a guess, a minimum thickness of $4 R_{0}$ will be chosen. The resulting minimum sheet thickness for a 50,000 psi aluminum alloy then is $8 \mathrm{~mm}$ or $\frac{1}{3}$ in., which is quite substantial. Of course, the in-plane geometry and loading also must meet all the requirements of small scale yielding.

Initiation and propagation of fracture in carbon structural steels is very different in detail from that in aluminum alloys. Strain-rate sensitivity produces an instability in the process. Cleavage of grains becomes more and more dominant the faster the crack advances. Temperature sensitivity of the yield strength and the entire flow curve also is most important. Nevertheless, the process of initiation in undamaged hot-rolled structural steel is extremely ductile. Just as in aluminum alloys, it requires a separation process and a ductile joining of the resulting cracks or voids.

Larger dimensions result from two of the important numerical differences between the properties of hot-rolled carbon steel and structural aluminum. A grain size order of dimensions, say $200 \mu$, seems more appropriate than the 50 for aluminum based on void site spacing. Also, the modulus of elasticity is three times larger. Consequently, the minimum $R_{0}$ required is 12 times larger for material of the same yield strength, $1,200,000 / \sigma_{0}, \mathrm{~mm}$, approximately. A steel of 50,000 psi yield strength requires a $24 \mathrm{~mm}$ or about $1 \mathrm{in}$. extent of the plastic zone and a $4 \mathrm{in}$. minimum thickness of plate to ensure plane strain initiation conditions on the basis of the assumptions made.

The minimum thickness required for a high strength steel, $\sigma_{0}=250,000$ psi, with its smaller distances between initiation sites is about the same as for a strong structural aluminum alloy. When the fracture process is viewed in terms of deformation rather than load, there is more similarity than difference in detail between a structural aluminum and a high strength steel of small grain size.

There is, however, a third important numerical difference between undamaged hotrolled carbon structural steel and most structural aluminum alloys or high strength 
steels. Under homogeneous conditions, the strain needed to open cracks or voids at moderate temperatures and strain rates is far higher. In general, the dimension of the zone of very large plastic deformation required for fracture is not set solely by the distance between initiation sites. The actual magnitude of the local strain is significant. Crack opening displacements for such very ductile steel must be appreciably greater than given by the ratio of the $200-50 \mu$ dimensions chosen in the preceding calculations. Conversely, of course, an embrittled steel will fracture at a still earlier stage, before the full development of the large deformation zone.

This point about the magnitude of the local strain in the zonc of large deformation was not brought out in the previous discussion. It is hidden in the expressions for strain variation within the large deformation region, and these have not yet been suitably analyzed. A guess is that the large deformation region extent might have to exceed the $200 \mu$ figure by a factor of 4 to account for the strain of order unity needed for fracture of highly ductile mild steel, as compared to much lower strain requirements in structural aluminums.

Multiplication of the previous value of one inch for $R_{0}$ by 4 to give the higher strain levels needed and by $50,000 / 30,000$ to convert to a 30,000 psi yield strength results in $R_{0}=7 \mathrm{in}$. (approx.) and a minimum thickness close to $30 \mathrm{in}$. for plane strain. On the other hand, the same steel embrittled by precompression to have a ductile extension range of only 0.02 strain and a yield strength of nearly $100,000 \mathrm{psi}$ [37,38] needs an $R_{0}$ of less than $\frac{1}{16}$ in. and a minimum sheet thickness below $\frac{1}{4}$ in. for plane strain brittle fracture.

The marked influence of local ductility appears even stronger in a very crude analysis [3] based solely on the linear elastic stress distribution and the choice of the same microstructural dimension $(100 \mu)$ for all metals. The key assumption made is that the single number of greatest importance is $\epsilon_{m}$, the maximum value of the tensile strain averaged over this governing microstructural length. An additional and very rough assumption is that $\epsilon_{m}$ is given closely enough by the average tensile stress of the linear elastic solution divided by Young's modulus. In the accompanying Table 1, plastic zone extents $R_{0}^{\prime}=0.002\left(\epsilon_{m} / \sigma_{0} / E\right)^{2}$ are tabulated on this basis for several materials: a very mild steel $\sigma_{4} / E=0.001$, a high strength steel or strong aluminum alloy $\sigma_{0} / E=0.007^{+}$, and the intermediate example of a steel with 100,000 psi yield or an aluminum alloy of 35,000 psi yield strength.

The $R_{0}{ }^{\prime}$ designation is employed to emphasize that this plastic zone extent is based upon the linear elastic solution reaching the yield stress $\sigma_{0}$ in tension, while the previous $R_{0}$ is the extent of the zone in which small but noticeable plastic deformation occurs based upon perfectly plastic analysis.

Table 1

\begin{tabular}{rrrr}
\hline \multicolumn{4}{c}{$R_{0}{ }^{\prime}$ (in.) for } \\
$\epsilon_{m}$ & $\sigma_{10} / E=0.001$ & $\sigma_{01} / E=0.0033$ & $\sigma_{0} / E=0.007^{+}$ \\
\hline 0.01 & 0.20 & 0.02 & 0.004 \\
0.02 & 0.80 & 0.08 & 0.016 \\
0.05 & 5.00 & 0.50 & 0.100 \\
0.10 & 20.00 & 2.00 & 0.400 \\
0.20 & 80.00 & 8.00 & 1.600 \\
0.80 & 1300.00 & 130.00 & 26.000 \\
\hline
\end{tabular}


There are enormous differences between the $1 / \sigma_{0}$ variation of the perfectly plastic solution and the $\left(1 / \sigma_{0}\right)^{2}$ of the linear elastic. The choice of where the truth lies between these two extremes is left to the reader. Either of the two sets of figures are quite spectacular, even with due allowance for errors of choice, and indicate the small likelihood of true plane strain fracture initiation in ductile sheet materials. However this is not so significant in practice as might be assumed. The fracture of inclusions or the cleavage of grains and the subsequent joining up will be delayed (require more local strain or work-hardening) in the absence of an out-of-plane tensile stress and the accompanying raised in-the-plane tension for yicld. Local fractures still will be initiated as the material strains and hardens. In fact, there would appear to be some compensation because local strains at the crack tip should be higher in the absence of the lateral constraint of plane strain. In the case of steel, especially when the mechanism of fracture is the joining up of cleavage cracks through ductile separation of the connected region remaining, transverse stress should have little influence. The low ductility figure of Table 1 combined with this lack of effect explain why steel embrittled by prestrain, nitriding, extremely low temperature, or high strain-rate does show plane strain crack initiation and propagation with small scale yielding.

The large size requirements for plane strain fracture inherent to highly ductile low yield strength metals are a well-known obstacle to laboratory $K_{I c}$ testing [10]. Perhaps our discussion in terms of a plasticity analysis and significant microstructural dimensions adds a rationale. Indeed, size requirements are so stringent that a critical plane strain stress intensity factor would appear not at all an appropriate toughness measure in many circumstances, and a need for study of fracture under constraint conditions far from this idealization is indicated for economical design.

\section{PLANE STRESS AND VARYING TRANSVERSE CONSTRAINT}

The problem of fracture in plate materials is essentially three-dimensional when the in-plane dimensions of the plastic regions are comparable to the thickness dimension. Little analytic progress has been made, and methods of analysis will have to be computer based. Important features are the rise of triaxiality through the thickness and deviations of strain patterns from the plane strain and two-dimensional plane stress idealizations. The latter theory becomes appropriate as dimensions of the plastic region approach sizes comparable to and larger than the thickness. Still, great accuracy in prediction cannot be expected within a thickness sized neighborhood of the crack tip.

Swedlow et al.[12] have presented computer solutions for two-dimensional plane stress. While the usual problems occur in the immediate vicinity of the tip, Hutchinson [15] has studied the structure of singularities in this case through techniques identical to those noted above for plane strain. The $r, \theta$ dependence of equivalent stress and strain is identical to that of (12). There the similarities end. No triaxiality is permitted and the region of intense strain spreads over a broad field in front of the crack as in Fig. 6(a), rather than above and below. It turns out to be rather important that these authors employed a Mises definition of first and subsequent yield surfaces, as illustrated by the elliptical curve shown in a principal stress plane. A very different non-hardening model was proposed by Dugdale [26]. He presumed yielding to be confined to a narrow slit-like region in front of the crack (Fig. 6(b)), with finite separations of surfaces in the plastic region opposed by the yield stress $\sigma_{0}$. Hahn and Rosenfield [27] verified the model experimentally, showing in etching studies on silicon iron that fully de- 

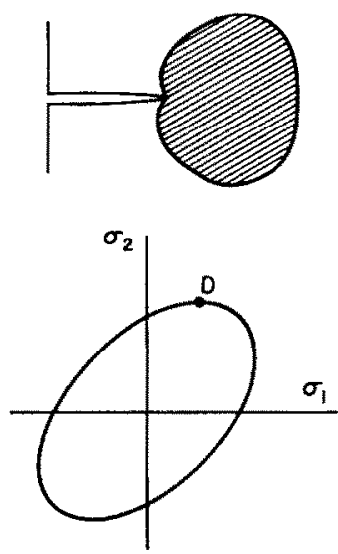

(a) MISES
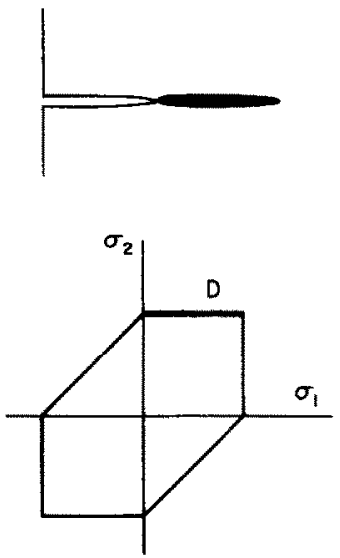

(b) DUGDALE OR TRESCA

Fig. 6. Dependence of plane stress yielding patterns on the yield criterion. Dugdale model is an exact two-dimensional plane stress solution for a Tresca material, but diffuse yield zones result for a Mises material. $D$ marks stress states permitting a neck extending ahead of the crack.

veloped plane stress yielding consisted of slip on broad intersecting bands at $45^{\circ}$ through the thickness. Separation displacements in the Dugdale model correspond approximately to average extensional strains in the narrow plastic zone multiplied by specimen thickness. The two plane stress analyses lead to drastically different predictions of the near tip field. For a given applied stress, Dugdale model strains vary inversely with thickness while Mises model strains have no dependence on thickness. Both patterns have been observed in experimental studies, the diffuse Mises type by Gerberich [28] for aluminum alloys.

We have made a careful study of the stress field in elastic regions of the Dugdale model, with computational assistance by Mr. G. F. Rosengren. Limiting attention to the small scale yielding field [2] for simplicity, it was found that the stress state of the Dugdale model violates neither the Tresca nor Mises criterion. If plastic flow rules are also satisfied, the Dugdale model presents an exact solution. Note that a normal displacement discontinuity is permissible within the framework of a two-dimensional plane stress perfect plasticity theory. The physical interpretation is in terms of throughthe-thickness slip. Normality of plastic strain increments to the yield surface [29] requires that the stress state be at the uppermost point $D$ on a Mises ellipse (Fig. 6(a)) to permit a normal discontinuity. Any stress state along the heavy line upper segment of the Tresca hexagon (Fig. 6(b)) will permit the discontinuity. Now the stress state of the Dugdale model along the discontinuity turns out to be equal biaxial tension at $\sigma_{0}$ for small scale yielding, with progressive decrease of the stress parallel to the discontinuity from $\sigma_{0}$ with large scale yielding. This stress state always permits the discontinuity in a Tresca material, but not in a Mises material. Thus the Dugdale model presents an exact two-dimensional plane stress solution for a Tresca material, for small scale yielding as well as at the limit load.

We do not suggest that all apparcnt ambiguitics in plane stress yielding are explained by classifying materials as Tresca or Mises or any other isotropic type. The important 
point is that plane stress plasticity patterns are very sensitive to the yield surface. This sensitivity does not show in plane strain, but might have been expected from the longitudinal shear case[2]. Anisotropy of properties when the thickness direction of rolled sheet materials is compared with in-plane directions would be a major factor in altering the shape of plane stress yield surfaces. Since the dependence of strains on thickness is totally different for diffuse as opposed to line plastic zones, a careful examination of the effect of the rolling process on yield patterns might provide a key to producing tough sheet materials. Conclusions on fracture instability as discussed in the next section will also vary with the yield pattern.

Plastic zone size and opening displacement for a large sheet of Tresca material containing a crack of length $2 a$ subjected to a remote tension $\sigma_{\infty}$, are [2] from the Dugdale model solution

$$
\begin{aligned}
R_{0} & =a\left[\sec \left(\frac{\pi \sigma_{\infty}}{2 \sigma_{0}}\right)-1\right]=\frac{\pi}{8} \frac{K^{2}}{\sigma_{0}^{2}}+\ldots \\
\delta_{t} & =\frac{8 \sigma_{0} a}{\pi E} \log \left[\sec \left(\frac{\pi \sigma_{\infty}}{2 \sigma_{0}}\right)\right]=\frac{K^{2}}{E \sigma_{0}}+\ldots
\end{aligned}
$$

First terms of the Taylor expansions give the small scale yielding result. Comparing these with the approximations of $(9,10)$ suggests a plane strain zone extent and opening displacement which are respectively 73 and 70 per cent of the plane stress values for $\nu=\mathbf{0 . 3}$ and for the same $K$. Rice has noted[14] that hardening and necking are readily included in the Dugdale model through the $J$ integral. If $\sigma(\delta)$ represents the restraining stress as a function of separation distance, as obtained by averaging stressstrain relations over the approximately thickness size plastic zone, the opening displacement is given by

$$
J=\int_{0}^{\delta_{t}} \sigma(\delta) \mathrm{d} \delta .
$$

\section{STABLE CRACK EXTENSION AND FRACTURE INSTABILITY}

The true incremental nature of plastic stress-strain relations has a profound effect on fracture instability. McClintock first pointed this out in elastic-plastic studies of longitudinal shear (mode III, or anti-plane strain) crack extension [30, 31], where the first increment of growth is found to be stable with continued growth requiring increasing load, until an instability is reached at which subsequent load drops would be required to maintain quasi static crack extension. The physical basis for this perhaps surprising behavior is made clear through the following example. Consider two materials having identical stress-strain curves for monotonic simple tension. One is nonlinear elastic; the other is elastic-plastic, recovering far less strain upon unloading. Suppose both are made into identical cracked specimens loaded by clamping portions of the boundary and imposing displacements. The deformation patterns around the crack tip will be similar in both. Now suppose the crack is cut ahead by a saw under fixed boundary displacements. The non-linear elastic material will readjust its strain pattern to that resulting had the displacements been imposed on a body with the now longer crack, so that a severe strain concentration remains at the tip. Cutting ahead in the elastic-plastic material produces little additional straining at the new crack tip. In the limit of a plastic-rigid material there will be no additional strain. This is easy 
to see by noting that we could loosen boundary clamps and no strain recovery would result. Then cut the crack ahead in the unloaded specimen. The specimen fits perfectly well into the tightened clamps again. The general feature leading to the rising deformation requirement for continued growth in a plastic material is the very stiff elastic response upon unloading (infinitely stiff for plastic-rigid) as contrasted with the soft tangent modulus response for both unloading and loading of a non-linear elastic material.

We follow Rice's [4] treatment in generalizing the McClintock longitudinal shear theory. First consider the monotonic anti-plane loading of a stationary crack in an isotropic non-hardening material. The shear strain at distance $x$ directly ahead of the tip is

$$
\gamma_{y z}=\gamma_{0} \frac{R_{0}}{x}
$$

where $R_{0}$ is the monotonically increasing extent of the plastic zone directly ahead of the tip. Now consider the opposite extreme for which the crack is quasi statically cut through the material with loads adjusted however appropriate to maintain a constant extent $R_{0}$ of the plastic zone directly ahead of the tip. The resulting steady state strain at distance $x$ from the moving tip is

$$
\gamma_{y z}=\gamma_{0}\left\{1+\log \frac{R_{0}}{x}+\frac{1}{2}\left[\log \frac{R_{0}}{x}\right]^{2}\right\}
$$

To see the great differences in these strain distributions, we follow McClintock and Irwin [31] in choosing as an approximate fracture criterion that a critical plastic strain $\gamma_{f}^{p}$ need be attained at a certain microstructural distance $\rho$ ahead of the crack. The resulting plastic zone sizes required to initiate fracture from a stationary crack and to maintain quasi static steady state extension are respectively

$$
\begin{aligned}
\left(R_{0}\right)_{\text {initiation }} & =\rho\left(1+\gamma_{f}^{p} / \gamma_{0}\right) \\
\left(R_{0}\right)_{\text {steady state }} & =\rho \exp \left(\sqrt{1+2 \gamma_{f} / \gamma_{0}}-1\right)
\end{aligned}
$$

The ratio of steady state to initiation zone sizes at fracture rises rapidly with ductility, being 3 when $\gamma_{f}{ }^{\prime \prime}=10 \gamma_{0}, 170$ when $\gamma_{f}{ }^{p}=50 \gamma_{0}$, and when $\gamma_{f}{ }^{p}=100 \gamma_{0}$.

One may show through a more detailed analysis [4] that the plastic zone dimension required to quasi-statically increase the crack length by distance $l$ is a universal monotonically increasing function $R_{0} f(l)$ of $l$ (for a given fracture ductility and microstructural dimension). The initiation extent above is $R_{0} f\left(0^{+}\right)$and the steady state extent is the asymptotic limit $R_{0} f(\infty)$. This type of function is shown by the heavy curve in Fig. 7 . where we measure $l$ from an initial crack length $a_{0}$. Now for any specific cracked configuration with loads proportional to a parameter $\mathcal{Q}$, we can obtain the plastic zone extent from the monotonic load analysis as some function $R_{\mathbf{0}}(Q, a)$ increasing with both $Q$ and crack length $a$. While it was an untested approximation in previous studies that this same function would give a good estimate of the zone size after some growth, recent and as yet unpublished computer results by A. Chitaley of M.I.T. verify the appropriateness of this approximation. Hence, the variation of load with crack length for 


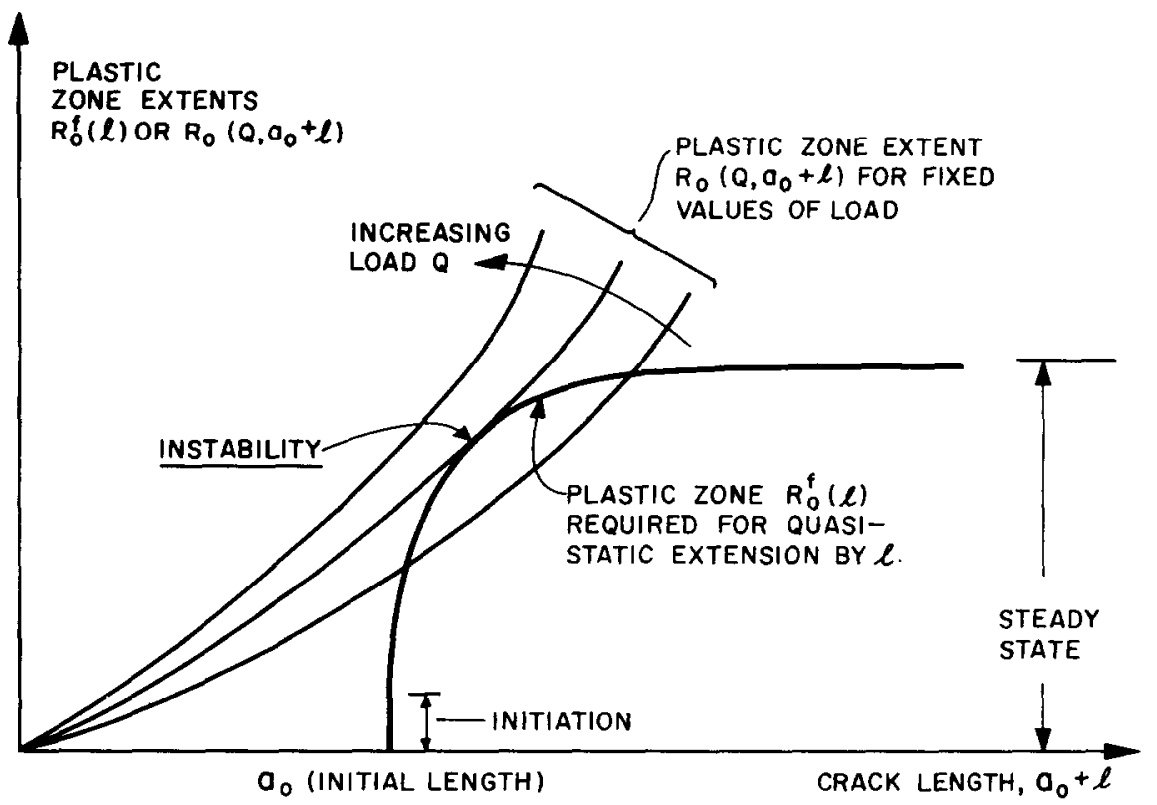

Fig. 7. Elastic-plastic stable crack extension and final instability, from anti-plane shear theory.

quasi-static extension is determined implicitly by solving $R_{0}\left(Q, a_{0}+l\right)=R_{0}{ }^{f}(l)$. Differentiating with respect to $l$, one finds the load drop instability to occur at a load $Q$ and growth $l$ simultaneously satisfying this equation and $\partial R_{0}\left(Q, a_{0}+l\right) / \partial l=\mathrm{d} R_{0}{ }^{f}(l) / \mathrm{d} l$. The geometric solution is shown in Fig. 7. Light lines represent the family of curves $R_{0}(Q, a)$ as functions of crack length for fixed values of the load. The member of this family in tangential contact with the heavy line simultaneously satisfies both equations. and thus marks the point of instability.

One reason for our presentation differing somewhat from McClintock's original papers is now evident. Figure 7 shows that the elastic-plastic theory of shear instability is in fact identical to the alternate 'resistance curve' analysis of instability by Krafft, Boyle, and Sullivan [32]. These authors employed Irwin's energy release rate where we have employed the plastic zone extent, and postulated a universal relation between the release rate and growth length. There is no distinction in the small scale yielding range for which the release rate is an appropriate measure of local conditions, for then it is proportional to the zone extent.

Stable growth under increasing tensile loads is most prominent in fully developed plane stress as shown, for example, by Broek's [33] recent studies on aluminum alloys. Here it is interesting to note that even when the elastic singularity appropriately sets boundary conditions on a small yielded zone, final fracture criteria obtained through the instability construction of Fig. 7 may differ significantly from a critical stress intensity factor criterion. Fractures involving contained plasticity in situations close to idcalizcd plane strain appear to be abrupt without prior growth. Somewhat less constrained fractures in plate materials do show stable growth [10], but this differs significantly from the picture envisioned above as gradual developments of shear lips accompany growth. 
No analysis of instability is presently available for the plane stress case. This would be a profitable research direction. Full incremental plasticity treatments are required as deformation formulations will not distinguish between crack advance and load elevation. Monotonic load plasticity patterns for the Mises material (Fig. 6(a)) are somewhat similar to the anti-plane case. Large plastic strains are focused into the tip from a diffuse yielded region directly ahead, with the crack advancing into material which is already permanently deformed, so that equally significant growth effects might be expected. The line plastic zone of the two-dimensional plane stress solution for a Tresca material will not lead to stable growth, but the actual three dimensional pattern modelled is diffuse on the scale of a thickness dimension. Analyses similar to the steady state computation leading to (17) would appear appropriate for describing the mechanical environment in stress corrosion crack advance.

\section{ENERGY BALANCE CALCULATIONS}

The great virtue of the Griffith approach to fracture, including the Irwin and Orowan modification for plastic deformation, lies in the possibility of obtaining a useful result without considering the detailed history of the fracture process. It can be predictive, therefore, only when comparing two situations in which the material which fails is in the same initial state and is subjected to essentially the same history. This limitation of scope is a consequence of the strong dependence of the local stresses and strains, of void growth and coalescence. and of cleavage and other means of separation on the entire path of loading and other environmental conditions as well as on the geometry of the specimen or structure.

When a linear elastic solution for a crack is used as a basis of a Griffith calculation, the apparent surface energy must include all energy dissipated in plastic deformation and is enormously greater than the true surface energy for ductile metals. An energy balance of this type is properly predictive of fracture only if the work of plastic deformation per unit extension of the crack remains constant or decreases as the crack progresses. This balance is useful in analysis and design, although such a constant cannot be a material property, whenever it can be found from the test of suitable specimens in the laboratory.

If an elastic-plastic solution is chosen as the basis for calculation, the plastic deformation throughout the main volume of material is taken into account. Therefore it cancels out in the energy balance which applies up until the point of instability or decrease of nominal stress associated with necking through the thickness in plane stress, or in the ligaments between coalescing voids, or the combination of cleavage and the rapid joining up of cracks. In the real problem, consequently, it is the energy dissipation associated with the unstable stage which should appear as surface energy. Were there no unstable plastic stage in the joining up of voids and cracks, the elastic or atomic force instability would remain and give the true surface energy term when the kinetic energy released is ignored. Except, perhaps, in the presence of a strongly corrosive atmosphere at the crack tip, the plastic term still overwhelms the true surface energy.

The distinction between the energy of unstable separation and the bulk dissipation is extremely important because the two can be quite different. In the small scale yielding problem when cracks are long and nominal stresses and strains are low, a metal with high yield strength and excellent elongation in 2 in. in the standard tension test may 
be markedly inferior to a weaker metal with much smaller elongation in 2 in. but which opens up many voids at low stress and locally pulls out like taffy.

Irreversibility of plastic deformation has an unfortunate and rather peculiar effect on the prediction of stability or instability of crack growth through an energy balance calculation. Its significance is made clearer when a general point of view is adopted which includes linear elastic, nonlinear elastic, elastic-perfectly plastic, and elasticwork-hardening materials as special cases. Figure 8 compares a loaded body in an initial state (a) and a final state (b). One or more cracks have extended in going from (a) to (b).

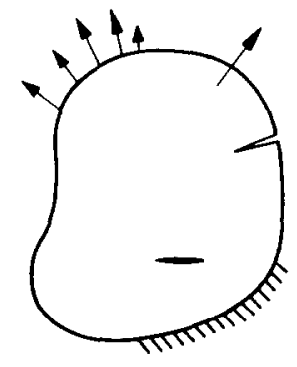

(a)

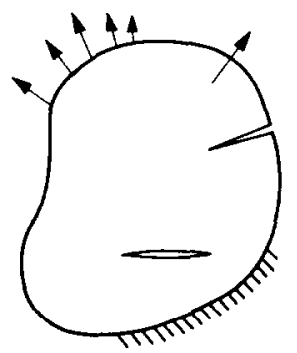

(b)

Fig. 8. Loaded body before (a) and after (b) crack extension, for energy balance considerations.

The result (Rice and Drucker [39]) is that the total release of mechanical (potential) energy, over and above the change in stored energy of the body and any plastic dissipation is

$$
\int_{V}\left[\int_{\epsilon_{w n}^{b}}^{\epsilon_{n+m}^{n}}\left(\sigma_{i j}-\sigma_{i j}^{b}\right) \mathrm{d} \epsilon_{i j}\right] \mathrm{d} V
$$

The path of integration is from (b) to (a), and the integrand would be positive for all stable elastic and elastic-plastic materials (Drucker[29]) which followed that path. Unfortunately, the material is taken from (a) to (b), not the other way around. The only immediate, direct, and general statement that follows is the inverse one that crack healing absorbs potential energy. Of course this can be turned around for linear or nonlinear elastic materials because they are reversible. Crack extension does release energy in elastic bodies. If the energy release rate exceeds the amount needed for the creation of new surface, growth occurs at fixed loads. If the energy released is insufficient, the crack will not grow.

However, for elastic-plastic materials, crack extension may increase or decrease the potential energy of the system. Stable growth of small transverse cracks in a tension sheet under increasing load is permissible, therefore, although not necessary in an elastic-plastic body. It is never permissible in a linear or nonlinear elastic material.

The barricr to the static initiation of fracture also is hidden in the backward proof. $\Lambda$ crack can propagate in mild steel at far lower nominal stress than the limit value needed for initiation of fracture. The release of energy given by the integral at working stress levels is very large if (a) represents a stationary crack and (b) is a running crack just infinitesimally longer. However, the ductility under static loading at working stresses is 
so high in undamaged steel that cleavage cannot be produced in a sufficient number of grains to permit the path from (a) to (b). Advantage cannot be taken of the apparent availability of energy. Cracks will not propagate unless the initiation barrier is overcome by such means as exceeding the limit load, or producing high local stress through dynamic loading, or embrittling the material at the root of the crack.

Similarly, if a comparison is made between plane stress and plane strain crack propagation in small scale yielding of thin sheets, the energy 'preference' for transition to plane strain is enormous. Such a transition may occur but energy balance alone does not provide the answer.

The removal of material from a loaded body, either mechanically or by chemical attack has the same effect on energy release as the extension of a crack just discussed. Interaction between chemical attack and the state of stress is one aspect of the stress corrosion problem. However, it seems likely that intergranular attack will lead to fracture more easily than bulk removal of material. Stress corrosion can be especially effective in lowering fracture strengths because it works directly on the local ductility and the energy needed to produce new surface. For example, if with time the tensile strength across grain boundaries is reduced to near zero, the fracture strength also goes to near zero no matter how much prior plastic deformation of the grains may have occurred. Similarly, any chemical embrittlement of the bulk material by gaseous diffusion either before voids have begun to grow and coalesce, or during the process of void growth when diffusion rates should increase, will decrease the critical local strain or equivalently the effective surface energy. Hydrogen embrittlement of steel might be a case in point but another explanation has been offered based upon the pressure produced by the hydrogen which causes cracking in the absence of externally applied stress [40]. Some rethinking of these and similar problems may be in order now that the relevant surface energy term has a somewhat clearer meaning. Westwood[41] has similarly emphasized the relevance of an appropriately defined surface energy term in environment sensitive behavior, even though its magnitude is generally negligible compared to overall plastic dissipation.

\section{LIMIT LOAD FRACTURES}

The real problem of (quasi-) brittle fracture in metal structures lies in the domain of contained plastic deformation discussed in the preceding sections. Such fractures still come as a surprise to the designer who knows his material to be amply ductile in the usual sense, able to take appreciable strain without rupture. He does in fact find it so, after the catastrophe, when he performs a standard tension test on a specimen cut from the failed structure. The same designer would expect (or at least not be surprised by) trouble at strain concentration points in the range of uncontained or fully plastic deformation. He recognizes that local strains then can be extremely large and exceed the ductility of the material.

Computation of the loads at which the deformation no longer is contained strongly by the elastic behavior of surrounding metal does not require elastic-plastic calculations with the actual stress-strain hehavior of the metal. This complexity can he avoided because a very satisfactory answer is given by the plastic limit load computed on the basis of an elastic-perfectly plastic idealization of the metal. Until the limit load is approached, strains everywhere are contained by clastic strains. Concentration factors may be high but the maximum strains remain moderate over regions visible to the 
unaided eye. The high strains on the microscopic level at the roots of sharp cracks have already been discussed, but they too are limited by the elastic constraint.

Once the limit load is reached, plastic strains are unconstrained. Infinite strain is possible with the perfectly plastic idealization. This must be interpreted as meaning that the maximum strains in a work-hardening material are of the order of plastic strains multiplied by a strain concentration factor which tends to be higher than the elastic factor. Clearly, if a material is at all prone to brittle fracture, it has a high likelihood of fracturing once the calculated limit load for the structure is reached or slightly exceeded.

Conceptually, the plastic limit theorems [42] which enable bracketing of the plastic limit load closely enough for practical purposes, play the same role in plasticity as the complementary energy and the potential energy theorems do in elasticity. Instead of dealing with equilibrium, compatibility, and stress-strain relations simultaneously, information is obtained from the use of an equilibrium stress field by itself and from a displacement (velocity) and an associated strain (velocity strain or strain rate) field by itself. The theorems are remarkably simple and in accord with intuition. When, as is customarily assumed for elastic solutions, changes in geometry are not taken into account in the equations of equilibrium and in the stress-strain relation, collapse (continuing plastic deformation) occurs under constant load and at constant stress. During collapse, strains are purely plastic.

\section{Theorem I (lower bound)}

The body will not collapse or will just be at the point of collapse if an equilibrium distribution of stress can be found which balances the applied load and is everywhere below yield or at yield.

\section{Theorem 2 (upper bound)}

The body will collapse if there is any compatible pattern of plastic deformation for which the rate at which the external forces do work equals or exceeds the rate of internal dissipation.

Theorem 1 expresses the ability of the material of the body to adjust itself to carry the applied load if there is any way of doing so. It gives lower bounds on, or safe values of, the plastic limit loading. The maximum lower bound is the plastic limit load. Theorem 2 states the fact that the body will not stand up if a permissible failure path exists. It gives upper bounds on, or unsafe values of, the plastic limit loading. The minimum upper bound is the plastic linit load.

A direct corollary of the lower bound Theorem 1 is that residual, thermal, or initial stresses or displacements do not affect the limit load. This corollary depends as do the limit theorems themselves, on an assumption of unlimited ductility of the material. If the local ductility and geometry combine to require limit load conditions for fracture in the absence of initial stress, the presence of such stress can suppress or enhance the danger at any load only very little. Small plastic deformations are sufficient to wipe out the residual pattern.

Computation of limit loads for symmetric thin notched sheets in tension, Fig. 9 is trivial when the Tresca yield criterion, Fig. 6(b), is employed. The limit force $P_{0}$ in tension is given almost exactly by the yield stress $\sigma_{0}$ in simple tension multiplied by the net cross-sectional area $(b-2 a) t$, where $b$ is the gross width, $a$ is the depth of each side notch or half the width of the internal crack, and $t$ is the thickness of the sheet. A small 

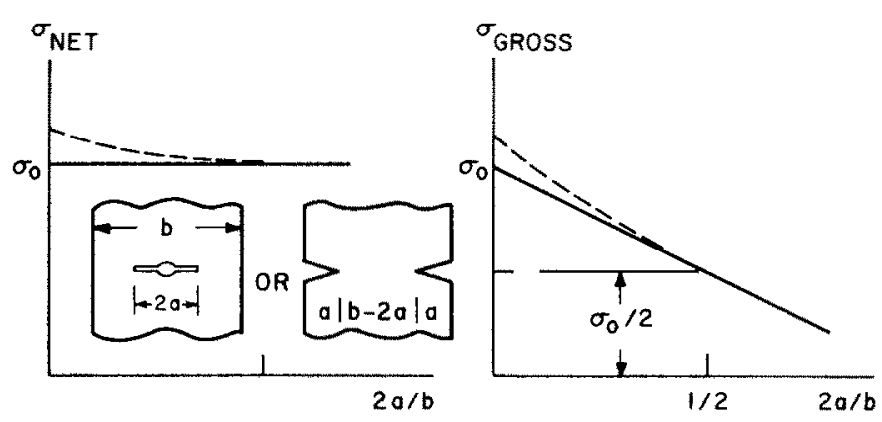

Fig. 9. Failure at or above limit load for a notched plate.

increase in the limit value is shown dashed in Fig. 9. This is to take into account the three-dimensional situation at the side notch roots and the small increase possible with the use of a Mises or intermediate criterion in lieu of the Tresca.

Test data on aluminum sheets of ample (but of course limited) ductility, and small to moderate width $b$, do confirm that failure follows such a curve. Yet errors in interpretation can and on occasion do arise even in this simplest of examples. If the nominal or gross stress at failure, $\sigma_{\text {gross }}=\rho_{0} / b t$, is plotted instead of the net stress, the data follow the falling line of Fig. 9. This is as predicted and well understood despite the temptation to associate such a drop with a quasi-brittle fracture below limit load.

It is easy to see how in more complex structures assembled from beam, plate, and shell elements the confusion between a nominal stress and a proper measure of plastic limit load could arise. This might well lead to an erroneous conclusion that a quasibrittle fracture had occurred when in fact, the plastic limit load had been reached or exceeded. Design procedures or analysis calculations of a nominal stress often allow for appreciable local changes in geometry from the actual fabricated configuration to a much smoother and more desirable structural shape. Such cold-forming under load will be satisfactory in an other wise well-fabricated mild steel structure at a sufficiently high temperature. It does, however, mean that limit loads are exceeded and that local strains are extremely high. The same smoothing of geometric shape at lower temperature or with a less ductile metal in the critical regions of the structure will produce a brittle appearing fracture at the plastic limit load for the structure as fabricated.

The fractures which occurred in low pressure storage vessels under hydrostatic test at $40^{\circ} \mathrm{F}$ are excellent if not happy cxamples [43]. Although designed in accordance with the code for ASME standard torispherical heads the limit load as calculated later by Shield and Drucker [44] was exceeded by the test pressure. A practical, yet not entirely satisfactory, solution is to use warm water in the hydrostatic test and so colddeform the vessel into a smoother shape of less curvature in the knuckle region.

In the earlier studies of the brittle fracture of ships [34] the opinion was expressed that the breaking of ships in two, most often represented a true very low stress fracture, a fracture far below limit load. The possibility, especially in the Liberty ships with insufficient attention to design details and to fabrication technique, that many of these fractures may have been much closer to a shell structure plastic limit load than first thought is worth investigation. If true, designs of mammoth ships can proceed with far greater confidence in survival under the most adverse sea conditions.

Questions of interpretation of laboratory as well as of field data also arise in simple 
spherical and cylindrical pressure vessels [3]. Suppose, as presented in [3], that a flat circular test plate of diameter $d$ and thickness $t$ is inserted in a spherical shell of diameter $D$, Fig. 10 . The test plate is subjected to membrane stretching and to transverse bending. No matter how small a crack is introduced into the test plate, the limit pressure is necessarily appreciably below the limit pressure for an uncracked fixed edge plate of diameter $d$ (Hopkins and Drucker [45])

$$
\begin{gathered}
\left(\pi \mathrm{d}^{2} / 4\right) p_{\text {limit }}< \\
(1.88) 6 \pi M_{0}=(1.88) 6 \pi\left(\sigma_{0} t^{2} / 4\right) \\
p_{\text {limit }}<11.3 \sigma_{0} t^{2} / \mathrm{d}^{2} .
\end{gathered}
$$

The limit pressure for a spherical shell of diameter $D$ and thickness $t$ is given by $\left(\pi D^{2} / 4\right) p_{\mathrm{sphere}}^{*}=\sigma_{0} \pi D t$ or $p_{\mathrm{sphere}}^{*}=4 \sigma_{0} t / D$. Therefore

$$
p_{\text {limit }}<(11 \cdot 3 / 4)\left(t D / \mathrm{d}^{2}\right) p_{\text {sphere }}^{*}
$$

When the test plate thickness is small and its diameter is moderate, $p_{1 \mathrm{~lm} t \mathrm{t}}$ is well below $p_{\mathrm{sphere}}^{*}$. For example, if $D=9 \mathrm{ft}, d=2 \mathrm{ft}$, and $t=\frac{3}{4}$ in., the limit pressure for the test plate is considerably less than $\mathbf{4 0}$ per cent of the limit pressure for a sphere of the same thickness and diameter $D$. The larger the crack in the test plate the smaller the limit pressure will be (see Fig. 12 of [46]).

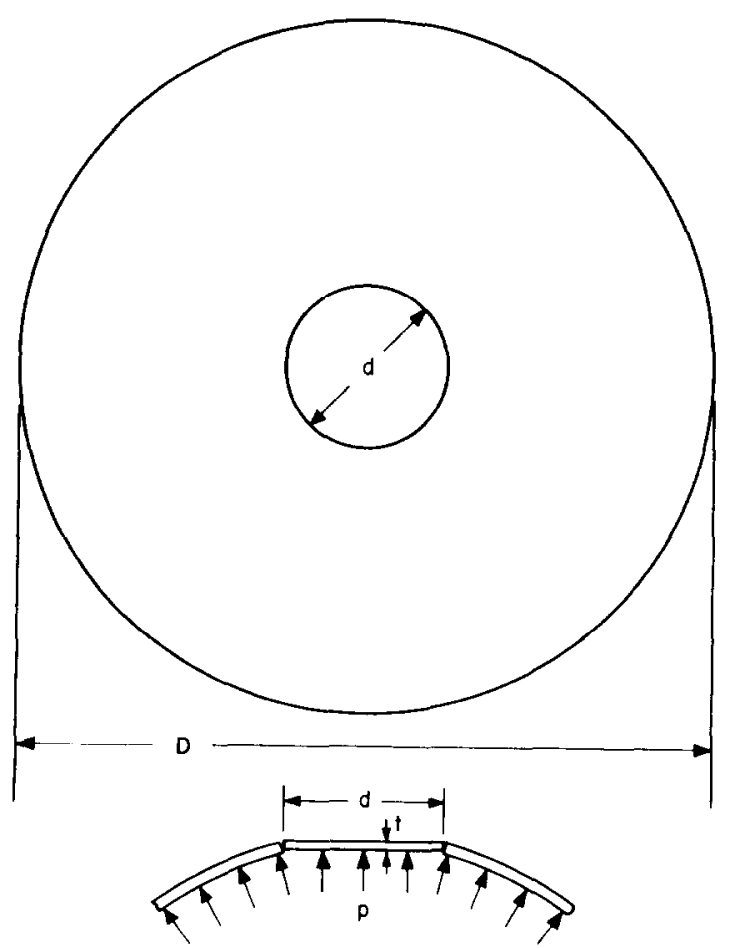

Fig. 10. Flat circular test plate inserted into a spherical shell. 
If the test plate remains ductile as the limit pressure is exceeded, it will bulge to assume an almost spherical form and so be able to carry the pressure as an almost perfect sphere. Similarly, if the pressure vessel with a torispherical head is deformed under interior pressure at a high enough temperature to avoid fracture, it too will be very much stronger under subsequent loading. The point remains, however, that when the limit loading is exceeded, local deformations do become very large and brittle fracture is all too likely.

A similar possible confusion between reaching limit pressure and reaching a pressure sufficient to cause a membrane tension equal to the yield strength or perhaps 80 per cent of the yield strength appears in the testing of cylindrical pressure vessels with a longitudinal crack or slit. Again, out-of-surface bending will give low limit loads when the slit is long enough.

Both the designer and the laboratory experimenter should become more aware of the distinction between limit load and net section stress concepts as they move away from the simple tension of thin flat sheets for which the distinction disappears. Plastic limit loads are always failure loads in the structural sense because deformations become excessive unless geometry change strengthening takes over strongly at an early stage. The factor of safety to be used must be greater if brittle fracture is likely than when the result is just a large change in shape and dimension.

\section{REFERENCES}

[1] D. C. Drucker, A continuum approach to the fracture of metals. In Fracture of Solids (Edited by D. C. Drucker and J. J. Gilman), pp. 3-50. Wiley, New York (1963).

[2] J. R. Rice, The mechanics of crack tip deformation and extension by fatigue. In Fatigue Crach Propagation, pp. 247-311. ASTM STP-415 (1967).

[3] D. C. Drucker, Macroscopic fundamentals in brittle fracture. In Treatise on Fracture (Edited by H. Liebowitz), Vol. 1. Academic Press, New York. (1968).

[4] J. R. Rice, Mathematical analysis in the mechanics of fracture. In Treatise on Fracture (Edited by H. Liebowitz), Vol. 2. Academic Press, New York. (1968).

[5] G. R. Irwin, Analysis of stresses and strains near the end of a crack traversing a plate. J. appl. Mech. 24, 361-364 (1957).

[6] M. L. Williams. On the stress distribution at the base of a stationary crack. J. appl. Mech. 24, 109 (1957).

17] P. C. Paris and G. C. Sih, Stress analysis of cracks. In Fracture Toughness Testing and Applications. pp. 30-76. ASTM STP-381 (1965).

[8] G. R. Irwin. Fracture mechanics. In Structural Mechanic's (Edited by J. N. Goodier and N. J. Hoff), pp. 557-591. Pergamon Press, Oxford (1960).

[9] P. C. Paris. The fracture mechanics approach to fatigue. In Fatigue-An Interdisciplinary Approach (Edited by J. J. Burke. N. L. Reed and V. Weiss), pp. 107-132. Syracuse University Press, Syracuse (1964).

[10] J. E. Srawley and W. F. Brown, Fracture toughness testing. In Fracture Toughness Testing and Applications, pp. 133-193. ASTM-STP-381 (1965).

[11] J. R. Rice, Stresses due to a sharp notch in a work hardening elastic-plastic material loaded by longitudinal shear. J. appl. Mech. 34, 287-298 (1967).

[12] J. L. Swedlow, A. H. Yang and M. L. Williams, Elasto-plastic stresses and strains in a cracked plate. Proc. Int. Conf. Fracture, Sendai, Vol. 1, pp. 259-282 (1965).

[13] P. V. Marcal and I. P. King. Elastic-plastic analysis of two-dimensional stress systems by the finite element method. Int.J.merh. Sci.9. 143-155 (1967).

[14] J. R. Rice, A path independent integral and the approximate analysis of strain concentration by notches and cracks. J. appl. Mech. 35. 379-386 (1968).

[15] J. W. Hutchinson. Singular behavior at the end of a tensile crack in a hardening material. J. Mech. Phys. Solid. 16, 1 s (1968).

[16] J. R. Rice and G. F. Rosengren, Plane strain deformation near a crack tip in a power law hardening material. J. Mech. Phys. Solid. 16, 1-12 (1968).

[17] W. Prager and P. G. Hodge, Theory of Perfectly Plastic Solids. Wiley, New York (1951).

[18] W. G. Clark, Jr., Visual observation of the crack tip plastic zone developed in a $3 \%$ Si-Fe alloy. Westinghouse Scient. Paper No. 66-ID6-BTLFR-P1 (1966). 
[19] G. T. Hahn and A. R. Rosenfield, Plastic zones generated by cracks growing under load. Int. J. Fract. Mech. 4 (1968).

[20] A. A. Wells, Application of fracture mechanics at and beyond general yielding. Br. Weld. J. 563-570 (1963).

[21] H. C. Rogers, Tensile fracture of ductile metals. Trans. metall. Soc. AIME 218, 498-506 (1960).

[22] F. A. McClintock, A criterion for ductile fracture by the growth of holes. J. appl. Mech. 35, 363-371 (1968).

[23] A. J. Wang, Plastic flow in a deeply notched bar with a semi-circular root. Q. appl. Math. 11, $427-438$ (1953).

[24] T. R. Wilshaw, C. A. Rau and A. S. Tetelman, A general model to predict the elastic-plastic stress distribution and fracture strength of notched bars in plane strain bending. Engng Fracture Mech. 1 , 191-211 (1969).

[25] J. M. Krafft, Correlation of plane strain crack toughness with strain hardening characteristics of a low, a medium, and a high strength steel. Appl. Math. Res. 88-101.

[26] D. S. Dugdale, Yielding of steel sheets containing slits. J. Mech. Phys. Solid. 8, 100-104 (1960).

[27] G. T. Hahn and A. R. Rosenfield, Local yielding and extension of a crack under plane stress. Acta Met. 13 (1965).

[28] W. W. Gerberich, Plastic strains and energy density in cracked plates: I. Experimental techniques and results. Exp. Mech. 4, 335-344 (1964).

[29] D. C. Drucker, Plasticity. In Structural Mechanics (Edited by J. N. Goodier and N. J. Hoff), pp. 407455. Pergamon Press, Oxford (1960).

[30] F. A. McClintock, Ductile fracture instability in shear. J. appl. Mech. 25, 582 (1958).

[31] F. A. McClintock and G. R. Irwin, Plasticity aspects of fracture mechanics. In Fracture Toughness Testing and Applications, pp. 84-113. ASTM-STP-381 (1965).

[32] J. M. Krafft, A. M. Sullivan and R. W. Boyle, Effect of dimensions on fast fracture instability of notched shects. In Proc. of the Crack Propn Symp., Cranfield College of Aeronautics (1961).

[33] D. Broek. Some considerations on slow crack growth. Int. J. Fract. Mech. 4 (1968).

[34] D. C. Drucker, An evaluation of current knowledge of the mechanics of brittle fracture. Ship Structure Com., Nat. Res. Council, Rep. No. SSC-69 (1954).

[35] D. C. Drucker, On obtaining plane strain or plane stress conditions in plasticity. Proc. 2nd U.S. Natn. Congr. Appl. Mech.,pp. 485-488. ASME (1954).

[36] W. N. Findley and D. C. Drucker, An experimental study of plane plastic straining of notched bars. J. appl. Mech. 32, 493-503 (1965).

[37] D. C. Drucker, C. Mylonas and G. Lianis, Exhaustion of ductility of E-steel in tension following compressive prestrain. Weld.J. Res. Suppl. 39, 117-120.

[38] C. Mylonas and K. C. Rockey, Exhaustion of ductility by hot straining - An explanation of fracture initiation close to welds. Weld.J. Res. Suppl. 40, 306-310.

[39] J. R. Rice and D. C. Drucker, Energy changes in stressed bodies due to void and crack growth. Int. J. Fract. Mech. 3, 19-27 (1967).

[40] A. S. Tetelman, The hydrogen embrittlement of ferrous alloys. In Fracture of Solids (Edited by D. C. Drucker and J. J. Gilman), pp. 671-708. Wiley, New York (1963).

[41] A. R. C. Westwood and M. H. Kamdar, Concerning liquid metal embrittlement, particularly of zinc monocrystals by mercury, Phil. Mag. 8(1963).

[42] D. C. Drucker, H. J. Greenberg and W. Prager, Extended limit design theorems for continuous media. Q. appl. Math. 9, 381-389 (1952).

[43] G. D. Galletly, Torispherical shells - a caution to designers. Trans. ASME (J. Engng Ind.) 81, 5 1-62 (1959).

[44] R. T. Shield and D. C. Drucker, Limit strength of thin-walled pressure vessels with an ASME standard torispherical head. Proc. 3rd U.S. Natn. Congr. Appl. Mech., pp. 665-672. ASME (1958).

[45] H. G. Hopkins and D. C. Drucker, Combined concentrated and distributed load on ideally-plastic circular plates. Proc. 2nd U. S. Natn. Congr. Appl. Mech., pp. 517-520. ASME (1954).

[46] ASME Subcommittee on Brittle Fracture (J. E. Srawley, chairman), A Revien of Engineering Approaches to Design Against Fracture. ASME (1965).

(Received 6 August 1968)

Résumé-Un effort particulier est fait pour couvrir la gamme complète plastique-élastique, depuis les fractures très importantes qui naissent et se propagent à une tension nominale ou nette, bien en bas de l'échelle élastique, jusqu'aux fractures communes, qui sont pourtant plus faciles à comprendre et à prévenir, dans des conditions de charge limite ou totalement plastique. On examine les similarités et les différences de comportement entre des aciers qui ont un taux de sensibilité très élevé, et des alliages d'aluminium ou d'autres métaux plus insensibles. Les distinctions très marquées qui apparaissent entre les extrêmes bien par- 
ticuliers de tension plane et d'effort plan sont mises en évidence ainsi que leur relation avec l'échec concernant des structures et éléments complexes.

On étudie en détail l'extension de la fracture dans les conditions d'effort plan. el le rôle important de l’émoussage progressif est indiqué à la fois en limitant les tensions maximales possibles et en prévoyant une petite zone d'effort intense dans laquelle opèrent les mécanismes de fracture par la traction. La comparaison avec les dimensions microstructurelles appropriées conduit à une rationalisation des dimensions minimales d'épaisseur pour une fracture due à l'effort plan. On montre que les modèles limites de tension plane dans des tôles fissurées sont extrêmement sensihles al critère de limite. I e modèle Dugdale de ligne en zone plastique fournit une solution correcte pour un matériau Tresca non-durcissant. mais on obtient des zones diffuses pour un matériau Mises. Le rôle important de l'anisotropie est indiqué. Une extension stable sous une charge croissante apparaît comme une conséquence possible de lavance de la fracture dans un métal préalablement déformé. Les conditions pour une croissance stablè à l'encontre d'une croissance brutale. lopportunité des approches d'énergie compensée et les calculs de charge limite plastique sont aussi étudiés. Une tentative est effectuée pour donner une bonne perspective générale.

Zusammenfassung - Ein Versuch wird unternommen den gesamten elastischplastischen Bereich von den ausserst problematischen Brüchen, die bei Nenn- oder Nettospannungen weitab im elastischen Bereich auftreten und fortschreiten, bis zu den häufigen. wenn auch leichter verständlichen. und verhinderbaren Brüchen unter vollkommen plastischen oder Grenzlast-bedingungen zu crfassen. Ähnlichkeiten und Unterschiede in Verhalten zwischen Stählen, deren Verhalten in starkem Masse von der Belastungsgeschwindigkeit abhängt und Aluminium-legierungen bzw. anderen eher unempfindlichen Werkstoffen, werden untersucht. Die sehr deutlichen Unterschiede zwischen den speziellen Extremfällen des ebenen Spannungs- und des ebenen Dehnungszustandes. sowie ihre Bedeutung für das Versagen komplexer Konstruktionen und einzelner Bauteile werden aufgezeigt. Im Gegensatz dazu wird die Notwendigkeit betont in den meisten Schalenkonstruktionen die Biegungsbeanspruchung zu berüicksichtigen. Es wird gezeigt, dass es möglich ist. im Laboratorium, jedoch noch mehr auf der Baustelle, Grenzlasthriiche mit Niedrigspannungshrijchen zu verwechseln.

Die Risserweiterung in ebenen Dehnungszustand wird ziemlich detailliert untersucht, und die wichtige Rolle einer fortschrietenden Abstumpfung der Rissespitze sowohl im Hinblick auf eine Begrenzung der maximal erzielbaren Spannungen, als auch auf die Bildung eines kleinen Bereiches intensiver Dehnung, wo duktile Bruchmechanismen wirksam werden, wird angedeutet. Ein Vergleich mit geeigneten mikrostrukturellen Abmessungen führt zu einer logischen Grundlage für Mindest-Dickenmasse für Brüche im ebenen Dehnungszustand. Es wird gezeigt. dass Fliesslinien für den ebenen Dehnungszustand in Blechen mit Rissen äusserst empfindlich gegenüber dem Fliesskriterium sind. Das Modell nach Dugdale liefert eine korrekte Lösung für ein nichtverfestigendes Tresca Material, während für ein Mises Material diffuse Zonen erhalten werden. Die wichtige Rolle der Anisotropie der Dickenrichtung wird angedeutet. Eine stetige Risserweiterung unter zunchmender Belastung kann als mögliche Folge eines Fortschreitens eines Risses in vorher verformtes Material angesehen werden. Die Bedingungen für stetes im Gegensatz zu plötzlichem Rissewachstum, die Anwendbarkeit von Energiebilanz-Methoden, sowie Verfahren zur Berechnungen der plastischen Grenzlast werden ebenfalls untersucht. Es wird versucht all diese Aspekte im richtigen Verhältnis zueinand'r zu sehen. 